\title{
Sistem Informasi Geografis Penderita Malaria pada Kelurahan Cereme Taba Kota Lubuklinggau
}

\author{
Hutrianto $^{1}$, Firamon Syakti ${ }^{2}$ \\ ${ }^{1}$ Program Studi Teknik Informatika, Fakultas Ilmu Komputer Universitas Bina Darma \\ ${ }^{2}$ Program Studi Sistem Informasi, Fakultas Ilmu Komputer Universitas Bina Darma \\ Jl. Jendral Ahmad Yani Nomor 2 Seberang Ulu I Palembang, 30264 \\ e-mail: hutrianto@binadarma.ac.id, firamon@binadarma.ac.id
}

\begin{abstract}
Abstrak
Sesuai dengan undang-undang berkaitan dengan kesehatan yaitu undang-undang nomor 36 tahun 2009 menyatakan dengan jelas yaitu anggaran untuk kesehatan merupakan 5\% dari anggaran pendapatan dan belanja negara (APBN). Untuk itu perhatian dan kepedulian pemerintah menjadi sangan penting untuk dilakukan baik pemerintah tingkat nasional, provinsi, kabupaten, kecamatan atau bahkan pemeritnah tingkat kelurahan. Salah satu sektor yang patut diperhatikan yaitu sektor pencegahan berkaitan dengan penyakit malaria. Namun untuk melakukan pencegahan tersebut membutuhkan data yang valid serta aktual. Untuk itu di dalam penelitian ini dilakukan pengembangan sistem informasi geografis penderita malaria sebagai salah satu cara dalam penyajian informasi untuk penanggulangan oleh pemerintah. Dalam proses pengembangan sistem informasi geografis digunakan waterfall seabgai metode pengembangan dengan tahapan communication, planning, modeling, construction, dan deployment. Sistem informasi geografis yang dihasilkan memiliki fitur yang dapat menyajikan data pendertia malaria dengan atribut nama, jenis Malaria, RT, alamat, telepon dan lama menderita malaria dan telah dilakukan pengujian. Hasil pengujian menunjukkan semua komponen dapat berfungsi dengan baik.
\end{abstract}

Kata kunci: SIG, Penderita Malaria, Waterfall

\begin{abstract}
By the law relating to health, namely law number 36 of 2009 states clearly that the budget for health constitutes $5 \%$ of the state budget (APBN). For this reason, the attention and concern of the government become very important to be carried out either at the national, provincial, district, sub-district, or even village level government. One sector that needs attention is the prevention sector related to malaria. But to do this, prevention requires valid and actual data.

For this reason, in this research, the development of a geographic information system for malaria sufferers was carried out as a way of presenting information for countermeasures by the government. In the process of developing a geographic information system, a waterfall used as a method of development with stages of communication, planning, modelling, construction, and deployment. The resulting geographic information system has a feature that can present supplementary malaria data with the attribute name, type of malaria, RT, address, telephone, and duration of disease and has tested. The test results show all components can function correctly.
\end{abstract}

Keywords: GIS, Malaria sufferers, Waterfall

eISSN: 2477-3255, pISSN: 2086-4884

https://doi.org/10.31849/digitalzone.v10i2. 3134 


\section{Pendahuluan}

Kesehatan merupakan hak setiap warga negara di Indoensia. Kondisi tersebut tercermin dari kebijakan pemerintah dalam membuat kebijakan dalam bidang kesehatan. Sesuai dengan undang-undang berkaitan dengan kesehatan yaitu undang-undang nomor 36 tahun 2009 menyatakan dengan jelas yaitu anggaran untuk kesehatan merupakan 5\% dari anggaran pendapatan dan belanja negara (APBN) [1]. Dari kondisi tersebut dapat diketahui bahwa kesehatan merupakan komponen penting dalam bernegara dan berbangsa untuk mencapai tujuan kehidupan yang masyarakat yang sehat dan berbudi luhur. Untuk itu perhatian dan kepedulian pemerintah menjadi sangat penting untuk dilakukan baik pemerintah tingkat nasional, provinsi, kabupaten, kecamatan atau bahkan pemerintah tingkat kelurahan. Dalam memberikan anggaran, pemerintah mengalokasikan dana sesuai dengan tingkat kepentingan atau dengan kata lain seberapa urgen kondisi tersebut membutuhkan pendanaan.

Salah satu kondisi yang dibutuhkan pendanaan dalam bidang kesehatan yaitu pencegahan penyakit yang dianggap memiliki dampak yang luas bagi masyarakat. Salah satu penyakit tersebut yaitu penyakit malaria. Penyakit malaria sendiri merupakan penyakit yang terjadi pada perubahan iklim tropis seperti di Indoensia [2]. Kejadian penyakit ini akan menjadi bencana yang menimbulkan keresahan di tengah masyarakat. Penyebab terjadinya penyakit malaria tidak terlepas dari aktivitas yang dilakukan masyarakat itu sendiri, seperti banyaknya tempat atau lokasi yang tidak terawat/terkontrol sehingga dapat menimbulkan perkembangbiakan nyamuk sumber malaria itu sendiri [3]. Untuk itu agar penyebaran penyakit malaria dapat dikontrol dan dapat tertanggulai perlu adanya program pemerintah dan informasi yang berkaitan dengan penderita penyakit malaria itu sendiri. Kebutuhan informasi tersebut menjadi sangan penting karena program pemerintah dapat dilakukan jika memiliki data yang akurat.

Untuk menghasilkan informasi atau data yang akurat maka dapat dilakukan dengan cara penyediaan sistem informasi yang dapat memberikan informasi yang valid tentang keadaan penderita malaria itu sendiri. Data yang valid atau akurat menjadi sangan penting karena dalam melakukan penanggulangan penyakit malaria membutuhkan informasi sampai pada lokasi kejadian agar tindakan yang perlu untuk dilakukan dapat diberikan oleh pemerintah. Salah satu jenis sistem informasi yang memiliki kemampuan untuk memenuhi kebutuhan tersebut yaitu sistem informasi geografis (SIG). SIG merupakan sistem informasi dibuat sesuai data spasial dan non spasial sesuai geografis [4]. SIG juga dapat dijadikan penunjang dalam pengambilan kebijakan oleh pemerintah karena memiliki kemampuan dalam penyajian data berdasarkan lokasi [5]. Selain itu SIG dibuat pada berbagai perangkat dan operating system baik pada perangkat mobile maupun perangkat dekstop dan dengan jenis platform operating system yang berbeda pula [6].

Kajian yang berkaitan dengan sistem informasi geografis sendiri telah banyak dilakukan diantaranya adalah SIG berkaitan dengan valuasi jasa lingkungan mangrove hasil penelitian yang didapat yaitu pemetaan lahan mangrove yang digunakan untuk data dalam menganalisa kerentanan timbulnya penyakit [7]. Penelitian lain tentang SIG yaitu SIG yang digunakan untuk menampilkan sebarang penyakit yang diakibatkan dari nyamuk, Dalam penelitian ini hanya dihasilkan perancangan SIG berupa perancangan basis data dan proses SIG atau dengan kata lain tidak secara spesifik untuk penyakit malaria [8]. Sedangkan penelitian dengan objek yang sama yaitu tentang SIG malaria, yaitu SIG yang dibuat untuk memberikan sebaran malaria pada Sumba Timur, namun hasil penelitian yang didapat yaitu sebuah SIG berbasis desktop (stay alone) dan data yang penderita dikelompokkan berdasarkan puskesmas. Dalam penelitian ini juga sebaran yang dimasud hanya hasil diagnosa awal (terduga penderita) sehingga belum dapat tergambarkan dengan jelas [9]. Berdasrkan uraian yang dikemukakan diatas maka dalam penelitian ini akan dilakukan pengembangan SIG yang digunakan untuk pemetaan penderita malaria. Dimana SIG yang akan dihasilkan dapat diakses semua pihak (berbasis web) dan data 
yang digunakan dalam pemetaan adalah penderita malaria. Dengan adanya SIG sebaran penderita malaria ini diharapkan dapat membantu dalam menyajikan data pendertia malaria dan sebarannya sehingga tindakan yang perlu dapat dilakukan, baik oleh pemerintah, lembaga swadaya masyarakat ataupun masyarakat itu sendiri.

\section{Metode Penelitian}

\subsection{Metode Penelitian}

Metode peneltian yang pakai untuk menguraikan penelitian yaitu menggunakan metode deskriptif. Metode ini telah digunakan diberbagai peneltian untuk mengungkapkan atau menjabarkan berbagai kejadian atau fakta. Metode deskriptif juga mampu untuk menjelaskan fenomena dan kejadian yang sedang berlangsung sesuai kaidah ilmiah secara actual dengan tujuan utama sebagai pemecahan atau jawaban sebuah masalah yang sedang dihadapi atau dilakukan oleh peneliti [10].

\subsection{Metode Pengembangan}

Dalam melakukan pengembangan sistem infromasi geografis penderita malaria pada Kelurahan Cereme Kota Lubuklinggau maka metode pengembangan yang digunakan adalah waterfall. Metode ini merupakan metode klasik yang bekerja secara sistematis dan berurutan dalam proses pegnembagan sistem informasi. Pada Gambar 1 dapat dilihat bagaimana proses pengembanga dengan waterfall [11].

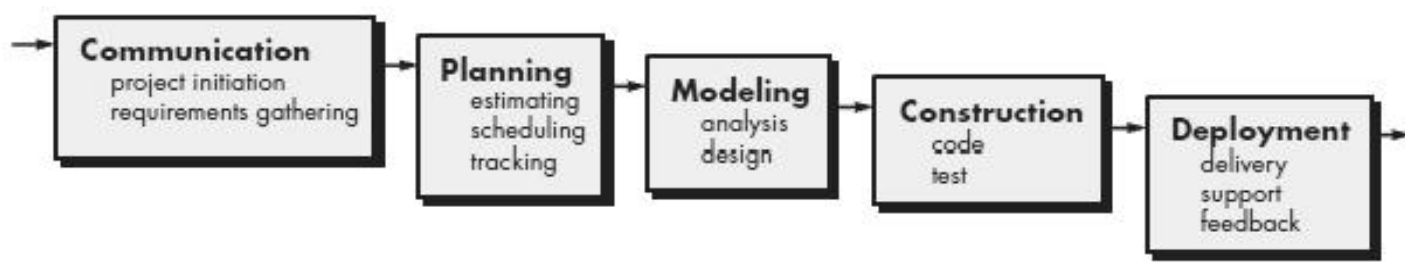

Gambar 1. Waterfall Model

a. Communication, pekerjaan yang dilakukan pada tahapan ini yaitu melakukan analisis untuk medapatkan kenutuhan sistem informasi. selain itu juga dilakukan pengumpulan informasi/data yang dianggap perlu dalam proses pengembangan.

b. Planning, proses pekerjaan yang dilakukan pada tahapan ini yaitu melakukan perencanaan dalam pengerjaan sistem informasi geografis penderita pernyakit malaria. Perencanaan yang dibuat berupa timeline kegiatan dan penyusunan daftar kebutuhan yang harus diselesaikan dalam proses pengembangan.

c. Modeling, pekerjaan yang dilakukan pada tahapan ini yaitu melakukan pembuatan model atau alur dari sistem informasi yang akan dihasilkan.

b. Construction, pekerjaan yang dilakukan pada tahapan ini yaitu melakukan yaitu melakukan pengkodean. Pengkodean yang dibuat mengikuti hasil modeling. Setelah selesai pengkodean dilakukan pengujian sistem infromasi.

c. Deployment, merupakan tahapan akhir yaitu melakukan persiapan delivery product. Selain itu juga dilakukan pemeliharaan terhadap product.

\subsection{Metode Pengujian}

Pengujian merupakan salah satu proses dalam pengembangan perangkat lunak. Pengujian dalam proses pengembangan untuk mengetahui sejauhmana perangkat lunak dapat bekerja dan bagaimana hasilnya. Untuk itu dalam melakukan pengujian digunakan metode black box testing sebagai metode pengujian. Black box testing merupakan teknik pengujian tanpa mengacu pada 
struktur internal perangkat lunak. Didalam Black box testing tidak membutuhkan seorang ahli dalam bidang programming ketika melakukan pengujian [12]. Dalam melakukan pengujian dengan teknik black box testing digunakan tiga jenis pengujian yaitu input, edit, dan delete. Ketiga jenis pengujian tersebut dilihat ketika sistem informasi geografis penderita malaria melakukan pengeolahan data.

\section{Hasil dan Pembahasan}

Setelah melakukan prosedur peneltian seperti yang dikemukakan pada sub bagian metode maka hasil yang didapat yaitu sebuah sistem informasi geografis penderita malaria pada Kecematan Cereme Kota Lubuklinggau. sistem informasi geografis penderita malaria pada Kecematan Cereme Kota Lubuklinggau ini memiliki fungsi utama yaitu untuk menampilkan informasi pemetaan lokasi sebaran penderita penyakit malaria yang ada di Kelurahan Ceremeh Kota Lubuklinggau. Di dalam sistem informasi geografis penderita malaria pada Kecematan Cereme Kota Lubuklinggau ini terdapat dua jenis pengguna yaitu masyarakat dan administrator. Masyarakat berperan sebagai pengguna biasa atau hanya dapat melihat data sedangkan administrator dapat melakukan pengolahan data. Pada Gambar 2 dapat dilihat struktur menu yang dihasilkan pada sistem infromasi geografis penderita malaria.

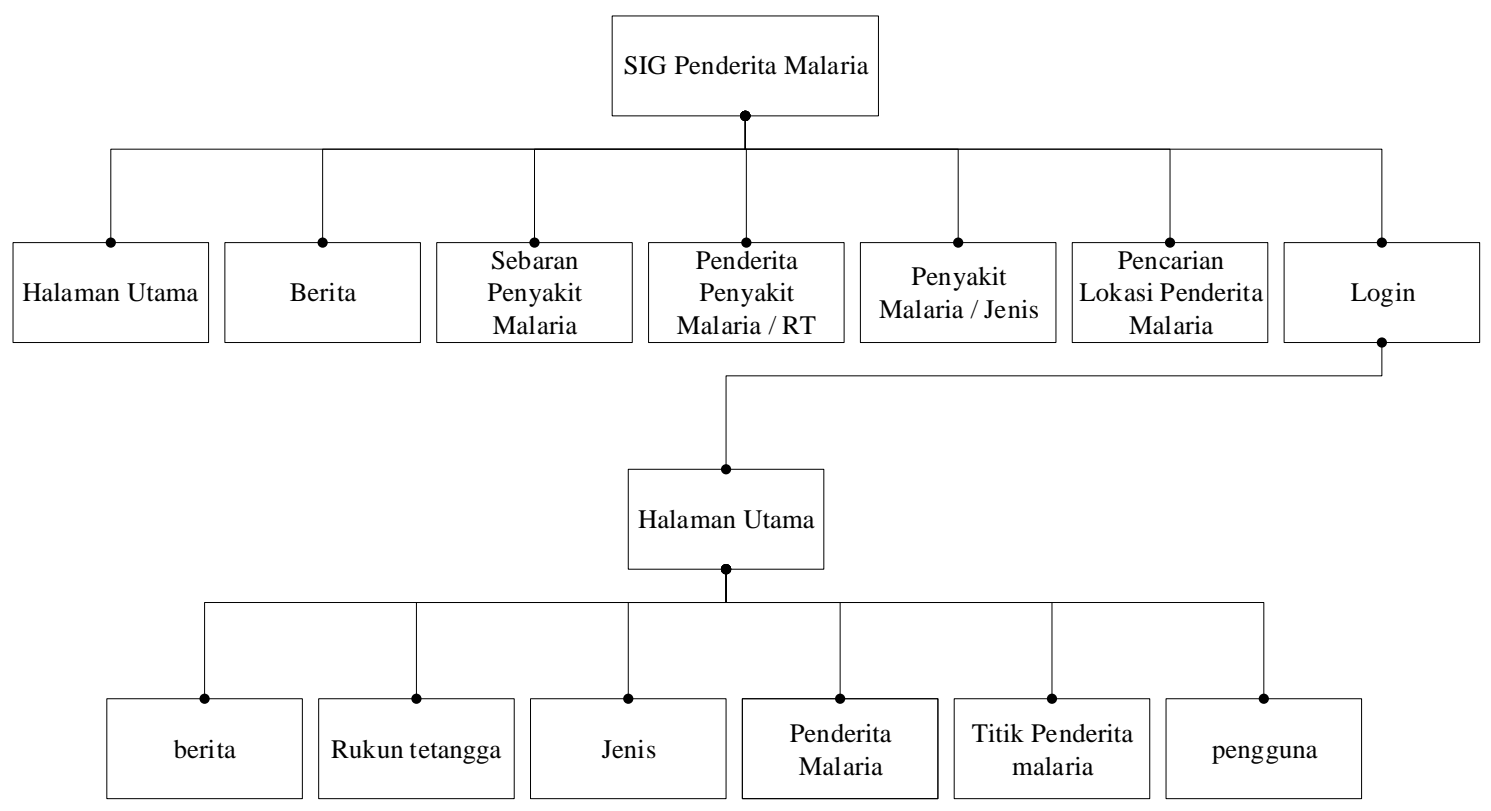

Gambar 2. Strukut Menu SIG Penderita Malaria

Dari halaman yang dibentuk pada sistem informasi geografis penyebaran penderita Malaria di Kelurahan Cereme Taba Kota Lubuklinggau maka masing-masing informasi untuk masing-masing halaman adalah sebagai berikut.

1) Halaman Halaman Utama, halaman ini merupakan merupakan tampilan utama dari Sistem Informasi Geografis Penyebaran Penyakit Malaria di Kelurahan Ceremeh Taba Kota Lubuklinggau . Pada halaman utama ini berisikan peta kelurahan Ceremeh Kota Lubuklinggau.

2) Halaman Berita, Halaman ini adalah halaman yang menyajikan informasi berita seputar kelurahan Ceremeh. 
3) Halaman Sebaran Penyakit Malaria, halaman ini adalah halaman yang berisikan informasi sebaran semua penderita penyakit malaria yang ada di Kelurahan Ceremeh Kota Lubuklinggau.

4) Halaman Penderita Penyakit Malaria/RT, halaman ini adalah halaman yang berisikan informasi sebaran penderita penyakit malaria dilihat berdasarkan RT yang ada di Kelurahan Ceremeh Kota Lubuklinggau.

5) Halaman Pencarian Lokasi Pendeita Malaria, halaman ini adalah halaman yang berisikan informasi sebaran penyakit malaria dilihat berdasarkan nama.

6) Halaman Login, halaan login adalah halaman yang berisikan form login. Pada halaman inilah administrator Sistem Informasi Geografis Penyebaran Penyakit Malaria di Kelurahan Ceremeh Taba Kota Lubuklinggau dapat melakukan login untuk mengelola data.

Sistem Informasi Geografis Penyebaran Penyakit Malaria di Kelurahan Ceremeh Taba Kota Lubuklinggau bertujuan untuk memberikan informasi lokasi penyebaran penderita penyakit malaria serta letak keberadaanya sehingga masyarakat luas dapat memperoleh informasi secara cepat, tepat, dan akurat. Untuk menjalankan sistem informasi geografis penyebaran penderita malaria dapat melakukan akses. Setelah melakukan akses maka akan menampilkan halaman utama dari Sistem Informasi Geografis Penyebaran Penyakit Malaria di Kelurahan Ceremeh Taba Kota Lubuklinggau seperti gambar 3.

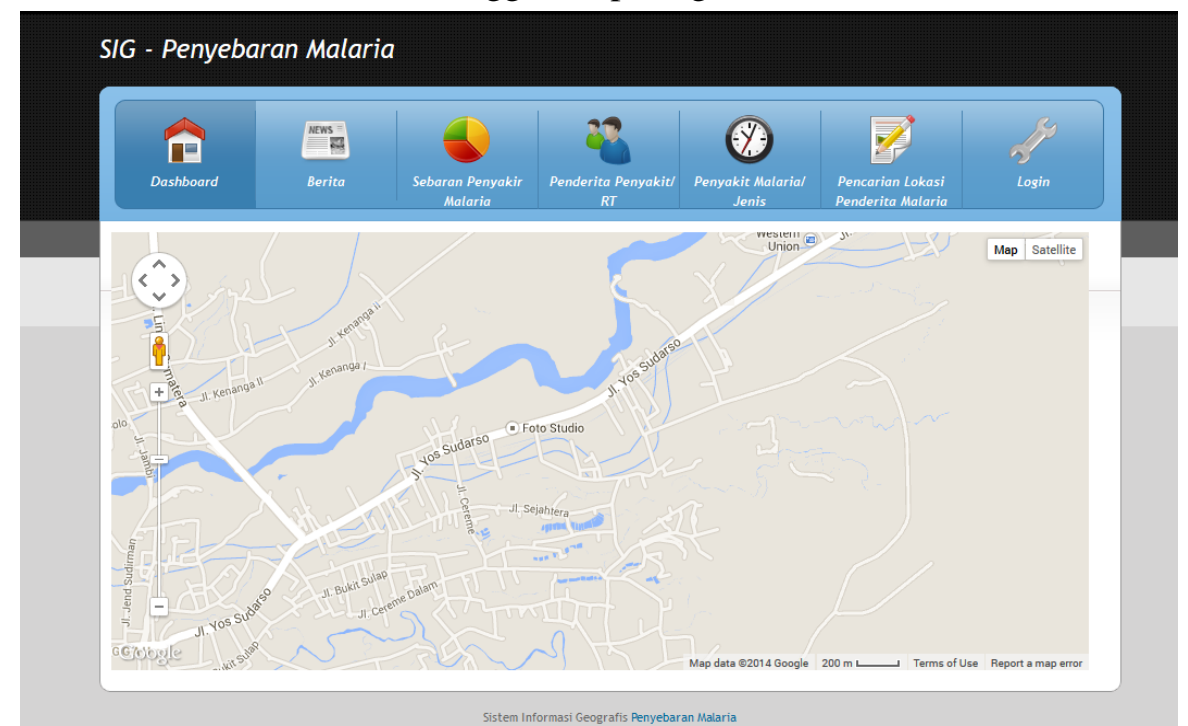

Gambar 3 Halaman Utama SIG Penderita Malaria

Dari halaman utama SIG penyebaran penderita malaria maka semua link yang berhubungan ke halaman lain yang ada pada SIG penyebran penyakit malaria dapat diakses. Halaman tersebut antara lain yaitu: (1) Halaman Berita, (2) Halaman Sebaran Penyakit Malaria, (3) Halaman Penderita Penyakit Malaria / RT, (4) Halaman Penyakit Malaria / Jenis, (5) Halaman Pencarian Penderita Penyakit Malaria dan (6) Halaman Login. Untuk masing masing halaman tersebut memiliki fungsi dan informasi yang berbeda-beda. Halaman berita merupakan halaman yang berisikan informasi berita yang berkaitan dengan sistem informasi penyebaran penyakit malaria atau yang berkaitan dengan penyebaran malaria. Pada gambar 4 adalah tampilan dari halaman berita. 


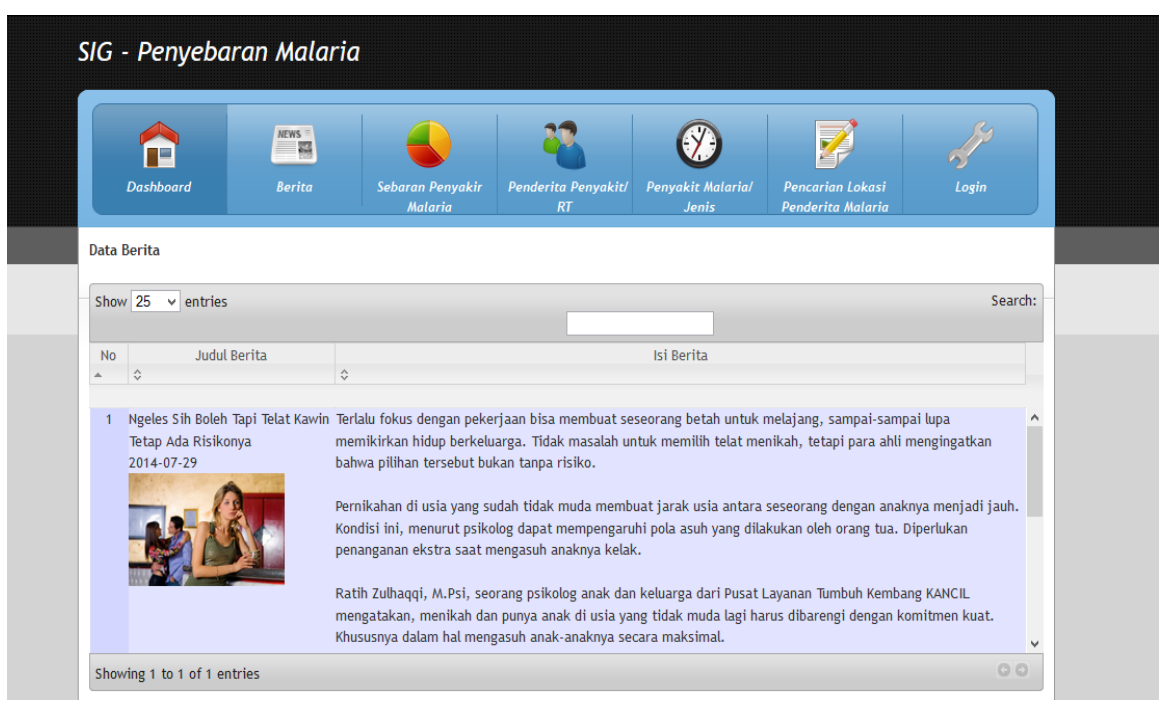

Gambar 4. Halaman Berita

Halaman selanjutnya yaitu halaman sebaran penderita penyakit malaria berisikan informasi lokasi-lokasi penderita penyakit malaria yang ada di Kelurahan Ceremeh Kota Lubuklingau. Penderita Penyakit Malaria yang ada adalah hasil penginputan oleh administrator SIG penderita penyakit malaria di Kelurahan Ceremeh Taba Kota Lubuklinggau. Pada sebaran Penderita Penyakit Malaria berisikan informasi seperti nama, jenis Malaria, RT, alamat, telepon dan lama menderita malaria. Pada Gambar 5 dapat dilihat tampilan dari sebaran penderita penyakit malaria untuk tingkat kelurahan.

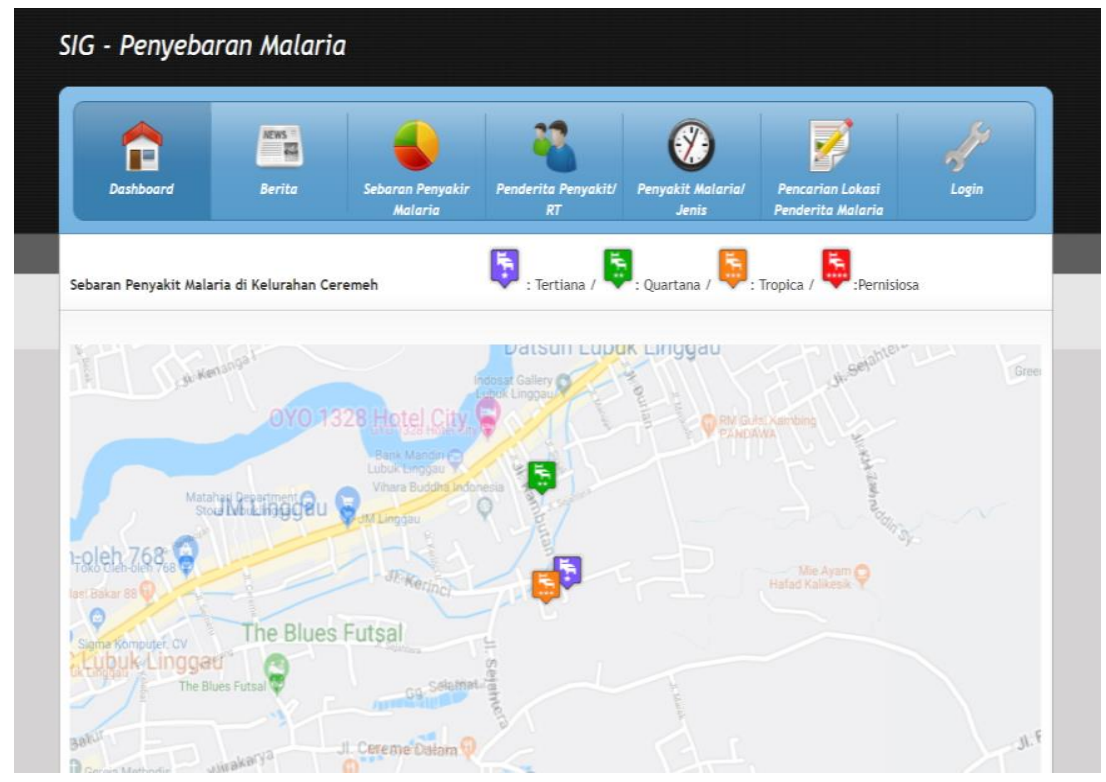

Gambar 5. Halaman Sebaran Penderita Penyakit Malaria Kelurahan

Selain menampilkan informasi sebarang penderita penyakit malaria untuk tingkat kelurahan maka SIG penderita malaria ini dapat juga menampilkan informasi penderita malaria untuk tinggkat rukun tetangga (RT). Untuk dapat melihat informasi ini pengguna dapat melihat 
pada halaman menu penderita penyakit/rt. Pada Gambar 6 dapat dilihat tampilan dari informasi penderita malaria berdasarkan rukun tetangga.

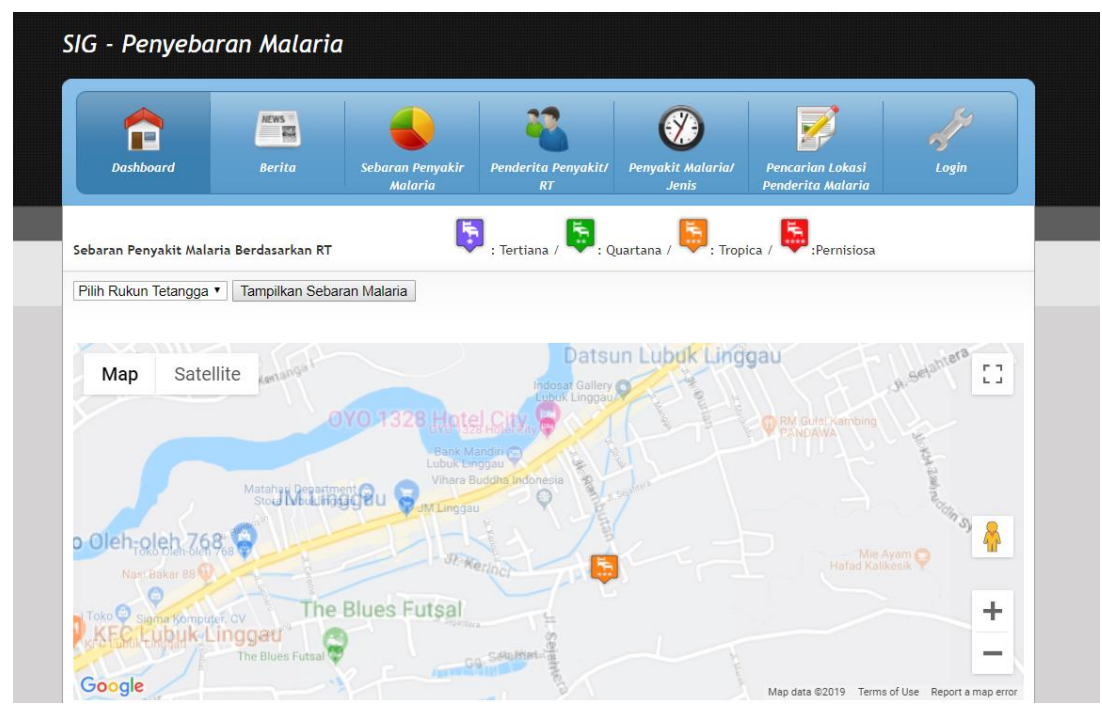

Gambar 6. Halaman Penderita Penyakit Malaria / RT

Untuk melihat informasi penderita penyakit malaria / jenis berdasarkan jenis malaria dapat dilihat melalui menu penyakit malaria /jenis. Jenis malaria tersebut antara lain adalah "tertiana merupakan malaria disebabkan oleh Plasmodium vivax, dimana penderita merasakan demam muncul setiap hari ketiga, quartana merupakan malaria disebabkan oleh Plasmodium mala-riae, penderita merasakan demam setiap hari keempat, tropica adalah malaria disebabkan oleh Plasmodium falci-parum, merupakan malaria yang paling patogenikdan seringkali berakibat fatal. Penderita Malaria jenis ini mengalami demam tidak teratur dengan disertai gejala terserangnya bagian otak, bahkan memasuki fasekoma dan kematian yang mendadak. Pernisiosa malaria ini disebabkan oleh Plasmodium ovale" [13]. Informasi yang ditampilkan pada menu ini adalah penderita malaria sesuai jenis yang dipilih oleh pengguna. Pada Gambar 7 dapat dilihat tampilan sebaran penderita penyakit malaria berdasarkan jenis malaria.

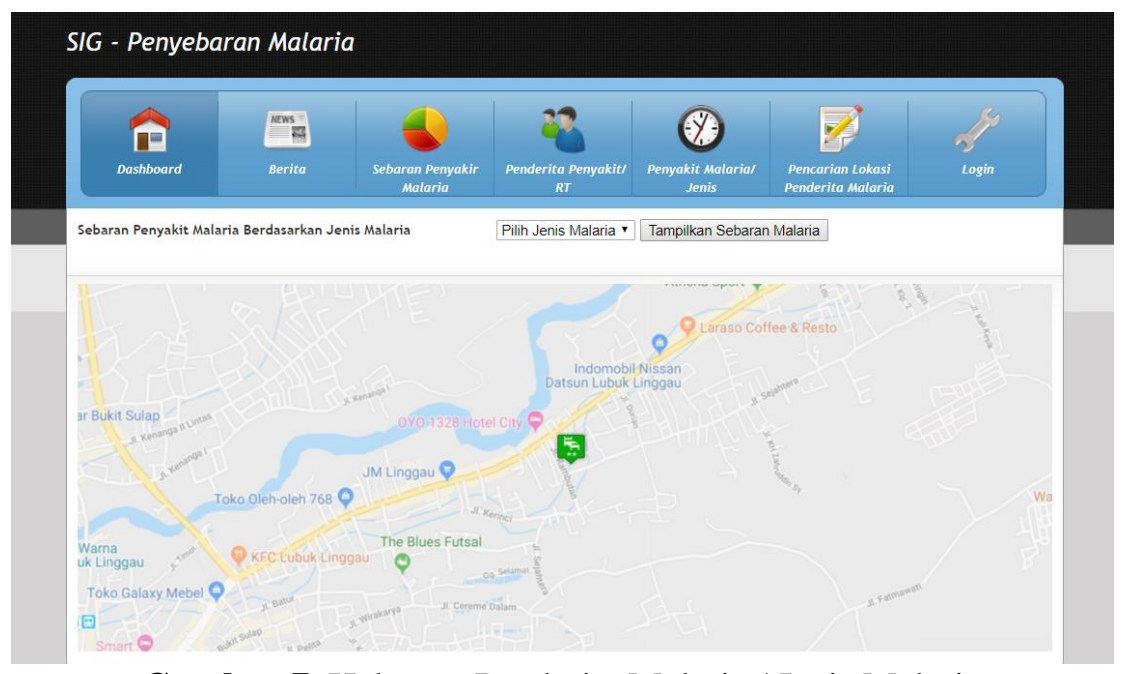

Gambar 7. Halaman Penderita Malaria / Jenis Malaria 
Untuk mengelola data dan informasi pada halaman SIG penderita malaria maka dapat dilakukan login melalui menu login. Menu login berfungsi sebagai jembatan untuk masuk ke halaman administrator SIG penderita malaria di Kelurahan Cereme Taba Kota Lubuklinggau. Pada gambar 8 tampak halaman login untuk masuk ke administrator.

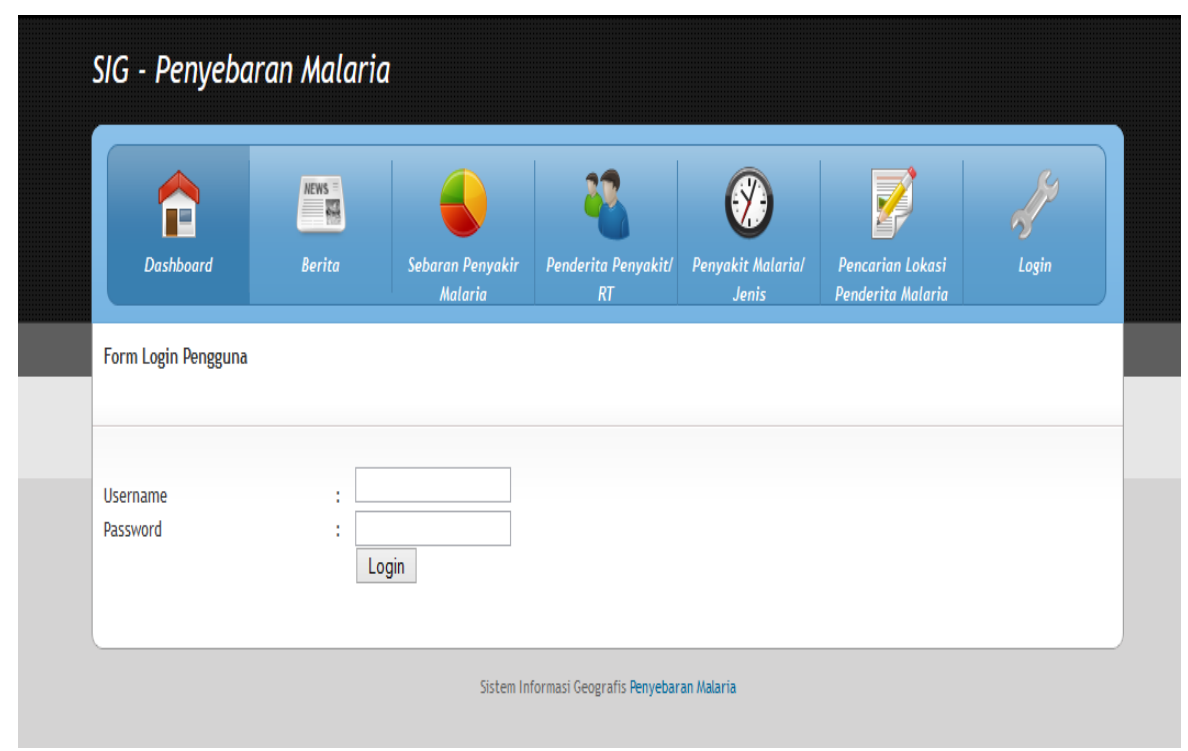

Gambar 8. Halaman Login

Setelah memasukan username dan password yang benar maka pada halaman login seperti yang diperlihatkan pada Gambar 8 selanjutnya administrator SIG penderita penyakit malaria maka dapat melakukan pengolahan data diantaranya adalah: (1) Data Berita, (2) Data Rukun Tetangga, (3) Data Jenis, (4) Data Penderita Malaria, (5) Data Titik Penderita Malaria. Berikut ini adalah tampilan halaman administrator setelah melakukan login dan dapat melakukan pengolahan data yang terlihat pada Gambar 9.

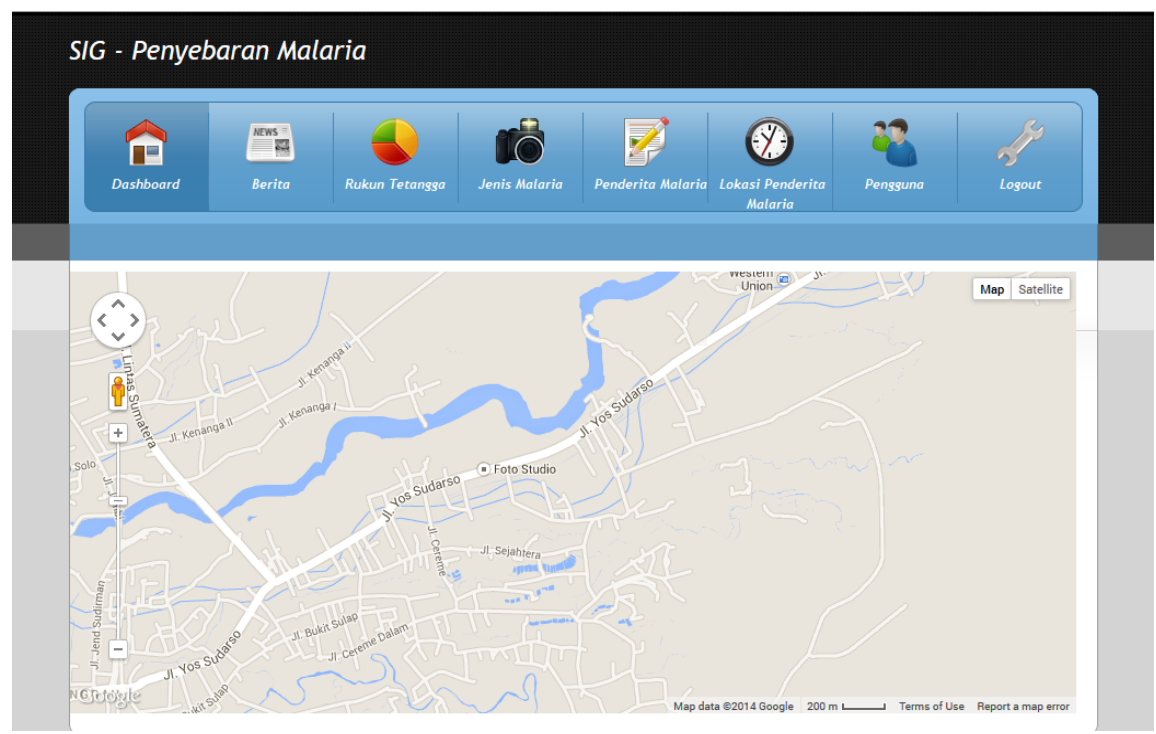

Gambar 9. Halaman Utama Administrator 
Selelah mengetahu hasil Sistem Informasi Geografis Penderita Penyakit Malaria di Kelurahan Ceremeh Taba Kota Lubuklinggau maka tahap selanjutnya mengetahu fungsionalitas dari masing-msaing komponen yang ada pada Sistem Informasi Geografis Penyebaran Penyakit Malaria di Kelurahan Ceremeh Taba Kota Lubuklinggau agar tidak terjadi kesalahan. Untuk itu dilakukan pengujian dengan blackbox testing. Cara pengujian dengan Sistem Informasi Geografis Penyebaran Penyakit Malaria di Kelurahan Ceremeh Taba Kota Lubuklinggau dengan melihat output-nya apakah telah sesuai dengan hasil yang diharapkan. Selanjutnya rencana pengujian yang dilakukan antara lain terdapat pada komponen-komponen seperti yang terlihat pada tabel 1 berikut ini.

Tabel 1. Rencana Pengujian

\begin{tabular}{|l|l|l|}
\hline \multicolumn{1}{|c|}{ Komponen Uji } & \multicolumn{1}{|c|}{ Detail Pengujian } & \multicolumn{1}{c|}{ Pengujian } \\
\hline Login & Pengguna dengan level administrator & Black box \\
\hline Berita & entri, ubah dan hapus data berita & Black box \\
\hline Rukun Tetangga & entri, ubah dan hapus data rukun tetangga & Black box \\
\hline Jenis & entri, ubah dan hapus data jenis malaria & Black box \\
\hline Penderita Malaria & entri, ubah dan hapus data penderita malaria & Black box \\
\hline Titi Penderita Malaria & $\begin{array}{l}\text { entri, ubah dan hapus data titik lokasi penderia } \\
\text { malaria }\end{array}$ & Black box \\
\hline
\end{tabular}

Sesuai dengan rencana pengujian seperti yang diperlihatkan pada Tabel 1 maka hasil pengujian terhadap SIG penderita malaria dapat diluhat pada Tabel 2 berikut ini.

Tabel 2. Hasil Pengujian

\begin{tabular}{|c|c|c|c|}
\hline Komponen Uji & Proses Pengujian & Pengujian & Hasil \\
\hline Login & $\begin{array}{l}0=0 D 0 \\
\square=\end{array}$ & Black box & Diterima (Accepted) \\
\hline Berita & 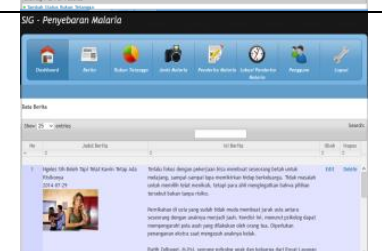 & Black box & Diterima (Accepted) \\
\hline Rukun Tetangga & 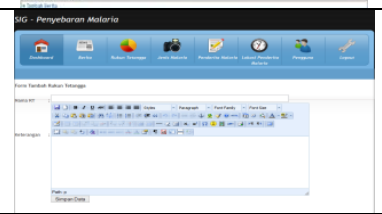 & Black box & Diterima (Accepted) \\
\hline Jenis Malaria & 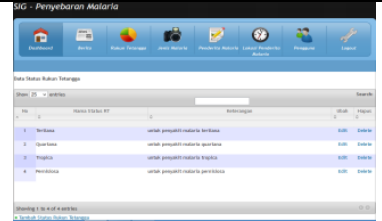 & Black box & Diterima (Accepted) \\
\hline
\end{tabular}




\begin{tabular}{|l|l|l|l|}
\hline Penderita Malaria & Black box & Diterima (Accepted) \\
\hline $\begin{array}{l}\text { Titik Penderita } \\
\text { Malaria }\end{array}$ & & Black box & Diterima (Accepted) \\
& & & \\
\hline
\end{tabular}

Hasil pengujian seperti yang diperlihatkan pada Tabel 2 menunjukkan bahwa semua komponen uji dapat berjalan dengan baik atau berfungsi dengan baik. Kondisi tersebut dapat diketahui dari hasil pengujian seperti yang diperlihatkan pada Tabel 2 dengan hasil pengujian diterima (accepted). Dengan demikian SIG penderita malaria dapat digunakan sebagai penyedia data informasi penderita malaria yang ada di Kelurahan Cereme Kota Lubuklinggau.

\section{Kesimpulan}

Sesuai dengan uraian yang telah dikemukakan berkaitan dengan sistem informasi geografis penderita malaria, dapat ditarik beberapa kesimpulan yaitu: (1) sistem informasi geografis penderita malaria yang dihasilkan dibuat secara tersetuktur menggunakan metode pengembangan waterfall. (2) sistem informasi yang dihasilkan dapat menampilkan informasi sebarang penderita malaria sehingga dapat dijadikan sebagai penyedia data penderita malaria. (3) sistem informasi geografis pendertita malaria juga dapat berfungsi dengan baik sesuai hasil pengujian yang menyatakan semua komponen berfungsi secara normal.

\section{Daftar Pustaka}

[1] D. K. R. Indonesia, "Undang-Undang Republik Indonesia Nomor 36 Tahun 2009 Tentang Kesehatan," vol. 12, 2009.

[2] s. Suwito, u. K. Hadi, s. H. Sigit, and s. Sukowati, "Hubungan iklim, kepadatan nyamuk Anopheles dan kejadian penyakit malaria," Jurnal Entomologi Indonesia, vol. 7, no. 1, p. 42, 2015.

[3] A. Munif, "Nyamuk vektor malaria dan hubungannya dengan aktivitas kehidupan manusia di Indonesia," ASPIRATOR-Jurnal Penelitian Penyakit Tular Vektor, vol. 1, no. 2, 2009.

[4] R. Arismunandar, "Sistem Informasi Geografis Sebagai Alat Monitoring Terhadap Apotek Kerja Sama PT Bayer Indonesia," Jurnal Nasional Teknologi dan Sistem Informasi, vol. 3, no. 1, pp. 187-198, 2017.

[5] K. I. Santoso and M. N. Rais, "Implementasi Sistem Informasi Geografis Daerah Pariwisata Kabupaten Temanggung Berbasis Android dengan Global Positioning System (GPS)," Scientific Journal of Informatics, vol. 2, no. 1, pp. 29-40, 2015.

[6] U. Ependi, "Geographic Information System Produksi Energi dan Pertambangan Kabupaten Musi Banyuasin," Jurnal Nasional Teknologi dan Sistem Informasi, vol. 3, no. 3, pp. 360-369, 2017.

[7] I. A. Qohar, S. Bakri, and D. W. Wardani, "pemanfaatan sistem informasi geografis untuk valuasi jasa lingkungan mangrove dalam penyakit malaria di provinsi lampung," in Prosiding Seminar Nasional Metode Kuantitatif, 2017, no. 1. 
[8] S. Wibowo, M. S. Lamato, A. I. Pradana, R. M. Aulawi, T. Indriyatmoko, and E. Utami, "Perancangan Sistem Informasi Geografis Penyebaran Penyakit Oleh Nyamuk di Provinsi Daerah Istimewa Yogyakarta," Duta, vol. 1, no. 10, p. 59, 2016.

[9] S. Rostianingsih, A. W. Kitu, and I. Gunawan, "Perancangan dan Pembuatan Sistem Informasi Geografis Untuk Penyebaran Penyakit Malaria," in Seminar Nasional Informatika (SEMNASIF), 2015, vol. 1, no. 4.

[10] U. Ependi and N. Oktaviani, "Abstract Keyword Searching with Knuth Morris Pratt Algorithm," Scientific Journal of Informatics, vol. 4, no. 2, pp. 150-157, 2017.

[11] R. S. Pressman, "Rekayasa Perangkat Lunak Pendekatan Praktisi (Edisi 7)," Yogyakarta: Andi, 2011.

[12] M. Kumar, S. K. Singh, and R. Dwivedi, "A Comparative Study of Black Box Testing and White Box Testing Techniques," International Journal of Advance Research in Computer Science Management Studies, vol. 3, no. 10, pp. 32-44, 2015.

[13] E. L. Febrianti and T. Christi, "Peneraan Forward Chaining Untuk Mendianogsa Penyakit Malaria Dan Pencegahanya Berbasis Web," JURTEKSI, vol. 4, no. 1, pp. 93100, 2017.

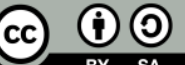

BY SA Digital Zone: Jurnal Teknologi Informasi dan Komunikasi is licensed under a Creative Commons Attribution International (CC BY-SA 4.0) 